\title{
Regional air pollution severity affects the incidence of acute myocardial infarction triggered by short-term pollutant exposure: a time-stratified case-crossover analysis
}

\author{
Chih-Chien Yen ${ }^{1,2} \cdot$ Ping-Ling Chen ${ }^{2}$ \\ Received: 22 April 2021 / Accepted: 27 August 2021 / Published online: 6 September 2021 \\ (C) The Author(s), under exclusive licence to Springer-Verlag GmbH Germany, part of Springer Nature 2021
}

\begin{abstract}
Long-term exposure to air pollution results in a high incidence of cardiovascular disease. Many studies have found that short-term exposure to air pollution can trigger acute myocardial infarction. This study aims to determine whether results in areas with different levels of severity of air pollution are similar. The study design is a time-stratified case-crossover analysis. This was a retrospective study based on hospital medical records. The study period was since 1 January 2017 to 31 December 2018. Research data were collected from Taoyuan Hospital, located in an area with low severity of pollution, and Taichung Hospital, located in an area with high severity of pollution. The correlation between short-term air pollution exposure and acute myocardial infarction was analyzed. The correlation between short-term exposure to ambient air pollutants and acute myocardial infarction was not significant for the cases collected from Taoyuan Hospital $\left(\mathrm{PM}_{2.5}\right.$ OR: 1.006 and $95 \%$ CI: 0.995-1.017; $\mathrm{PM}_{10}$ OR: 0.996 and 95\% CI: 0.988-1.003). However, for the cases collected from Taichung Hospital, short-term exposure to ambient $\mathrm{PM}_{2.5}$ (odds ratio: 1.021; 95\% confidence interval: 1.002-1.040) and $\mathrm{PM}_{10}$ (odds ratio: 1.010 ; $95 \%$ confidence interval: $1.001-$ 1.020) resulted in high incidence of acute myocardial infarction. Short-term pollutant exposure will increase the incidence of acute myocardial infarction based on the severity of regional air pollution. In addition to addressing traditional cardiovascular disease risk factors, the government must formulate relevant policies for reducing air pollution and the resulting hazards to citizens' health.
\end{abstract}

Keywords Particulate matter $\cdot$ Regional air pollution severity $\cdot$ Short-term effect $\cdot$ Acute myocardial infraction $\cdot$ Time-stratified case-crossover analysis

\section{Introduction}

Acute myocardial infarction is major disease that leads to poor health conditions (WHO 2016). It poses a heavy financial burden on families and requires considerable society-based treatment. Lelieveld et al. $(2019,2020)$ used novel hazard ratio functions to reassess cardiovascular disease burden due

Responsible Editor: Lotfi Aleya

Ping-Ling Chen

d513106002@tmu.edu.tw

1 Division of Cardiovascular Surgery, Department of Surgery, Taoyuan Armed Forces General Hospital, Taoyuan, Taiwan, Republic of China

2 Graduate Institute of Injury Prevention and Control, College of Public Health, Taipei Medical University, No. 250, Wu-Hsing St., Xinyi Dist., Taipei City 110, Taiwan, Republic of China to ambient air pollution in Europe. The results imply that reducing air pollution can substantially curb the reduction of life expectancy (see also Oikonomou et al. 2020). Through their respective national health policies, governments have been investing considerable effort into reducing the incidence of myocardial infarction. Moving away from the traditional risk factors for myocardial infarction, scholars are increasingly focusing on the correlation between air pollution and cardiovascular disease (Brook et al. 2004; Miller et al. 2007; Pope et al. 2006; Xie et al. 2015).

The main pathophysiological framework used to explain the epidemiological association between exposure to ambient air pollutants and acute myocardial infarction is an increase in the mean resting arterial blood pressure due to an increase in the sympathetic tone and regulation of potential systemic vascular tone. With a transient increase in plasma viscosity and the amount of endothelial function damage, the risk of intravascular thrombosis increases, thus promoting the 
development of atherosclerosis (Brook et al. 2002; Pekkanen et al. 2002; Sun et al. 2010; Rao et al. 2018).

Most studies note that long-term exposure to ambient air pollutants increases the incidence of cardiovascular disease. Many studies have found that short-term exposure to air pollution can trigger acute myocardial infarction. However, whether results are similar across areas with different levels of severity of air pollution remains unclear (Milojevic et al. 2014; Wichmann et al. 2014; Wolf et al. 2015).

This study aims to determine whether the difference in the severity of air pollution in the study area influences the difference between short-term exposure and incidence of acute myocardial infarction.

\section{Materials and methods}

This study was conducted at Taoyuan Hospital and Taichung Hospital, which are 450-bed academic regional emergency responsibility teaching hospitals; these hospitals are located in Taoyuan and Taichung, Taiwan (ROC), respectively. These hospitals are located in areas with low and high severity of air pollution, respectively. Data were obtained from a retrospective review of patient medical records, including the date of illness onset, gender, age, body mass index, hypertension, hyperlipidemia, diabetes, smoking, drinking, and heart disease history of the patient and their family. This retrospective study involved patients in Taoyuan and Taichung who received a diagnosis of acute myocardial infarction from 1 January 2017 to 31 December 2018. The diagnosis of acute myocardial infarction requires an elevated number of myocardial enzymes and confirmation by cardiac catheterization. Residents or workers who had not lived in the locality for more than 1 year were excluded from this study.

The Air Quality Monitoring Station of the Environmental Protection Agency of the Executive Yuan provided information on environmental air pollutants. Each monitoring station obtains hourly air pollutant data and provides the 24-haverage daily concentration of pollutants, including $\mathrm{PM}_{2.5}$, $\mathrm{PM}_{10}$, ozone $\left(\mathrm{O}_{3}\right)$, sulfur dioxide $\left(\mathrm{SO}_{2}\right)$, and nitrogen dioxide $\left(\mathrm{NO}_{2}\right)$, as well as the temperature and humidity.

We examined the associations between short-term air pollutant exposure and acute myocardial infraction by using a time-stratified case-crossover design. The levels of ambient air pollutants on the date of onset of illness were compared with those 2 weeks before the onset. Odds ratios (ORs) and 95\% confidence intervals (CIs) were estimated using Poisson regression in the generalized linear model. Models were adjusted for average temperature and relative humidity on the day of an event.

Categorical variables were compared between groups using the $\chi^{2}$ test and Student's $t$ test; continuous variables are presented as mean \pm standard deviation and were compared using the $t$ test. $P<0.05$ was considered statistically significant. Data analyses were performed using SPSS version 22 (SPSS, Chicago, IL, USA).

\section{Results}

Based on the medical records of emergency departments and hospitalization, this study recruited 352 and 278 patients respectively from Taoyuan and Taichung hospitals. The diagnosis of acute myocardial infarction requires elevated number of myocardial enzymes and confirmation by cardiac catheterization. Residents or workers who had not lived in the locality for more than 1 year were excluded from this study.

Table 1 presents the demographic and medical data of patients from Taoyuan Hospital. Most acute myocardial infarctions occurred in men $(76.40 \%)$. The average patient age was 62 years, and most of the patients were overweight $(25$ to $<30$ $\mathrm{kg} / \mathrm{m}^{2}$ ). Among the traditional risk factors, hypertension and smoking were significant. Table 2 presents the demographic and medical-related data of patients from Taichung Hospital. Again, most acute myocardial infarctions occurred in men $(71.58 \%)$. The average patient age was 66 years, and most of the patients were overweight $\left(25\right.$ to $\left.<30 \mathrm{~kg} / \mathrm{m}^{2}\right)$. Among the traditional risk factors, hypertension and smoking were significant here, as well. The cases in Taoyuan and Taichung mainly comprised male older adults (mean average is 62 years old; 66 years old). The major risk factors were overweight, high blood pressure, and smoking. Table 3 shows no significant difference demographic and medical-related variables between the cases collected from Taoyuan Hospital and those from Taichung Hospital.

Compared with the analysis of air pollution concentration conducted 2 weeks before the onset of disease in patients. The occurrence of short-term exposure to ambient air pollutants and the incidence of acute myocardial infarction were not significant in the cases collected from Taoyuan Hospital $\left(\mathrm{PM}_{2.5}\right.$ OR: 1.006 and $95 \%$ CI: 0.995-1.017; $\mathrm{PM}_{10}$ OR: 0.996 and $95 \%$ CI: 0.988-1.003) (Table 4). However, for the cases collected from Taichung Hospital, short-term exposure to the ambient air pollutants of $\mathrm{PM}_{2.5}$ (OR: 1.021; 95\% CI: 1.002-1.040) and $\mathrm{PM}_{10}$ (OR: 1.010; 95\% CI: 1.0011.020) increased the incidence of acute myocardial infarction (Table 5). $\mathrm{O}_{3}, \mathrm{SO}_{2}$, and $\mathrm{NO}_{2}$ displayed no significant correlations between short-term exposure of air pollution and incidence of acute myocardial infraction in Taoyuan and Taichung hospitals.

\section{Discussion}

The effects of short-term air pollution exposure and the incidence of acute myocardial infarction were found to be closely 
Table 1 Demographic and medical-related variables of the patients from Taoyuan Hospital

\begin{tabular}{|c|c|c|}
\hline \multirow[t]{2}{*}{ Acute myocardial infraction } & \multirow[b]{2}{*}{ Number } & \multirow[b]{2}{*}{ Percentage } \\
\hline & & \\
\hline Total & 352 & 100.00 \\
\hline \multicolumn{3}{|l|}{ Sex } \\
\hline Male & 269 & 76.40 \\
\hline Female & 83 & 23.60 \\
\hline Age & $62.90 \pm 14.89$ & \\
\hline \multicolumn{3}{|l|}{ Age group (years) } \\
\hline$<45$ & 42 & 11.90 \\
\hline $45-65$ & 157 & 44.60 \\
\hline$>65$ & 153 & 43.50 \\
\hline BMI $\left(\mathrm{kg} / \mathrm{m}^{2}\right)$ & $27.51 \pm 4.07$ & \\
\hline$<18.5$ & 8 & 2.30 \\
\hline 18.5 to $<25$ & 128 & 36.40 \\
\hline 25 to $<30$ & 178 & 50.60 \\
\hline$\geq 30$ & 38 & 10.80 \\
\hline \multicolumn{3}{|l|}{ Hypertension } \\
\hline Yes & 244 & 69.30 \\
\hline No & 108 & 30.70 \\
\hline \multicolumn{3}{|l|}{ Hyperlipidemia } \\
\hline Yes & 65 & 18.50 \\
\hline No & 287 & 81.50 \\
\hline \multicolumn{3}{|l|}{ Diabetes mellitus } \\
\hline Yes & 131 & 37.20 \\
\hline No & 221 & 62.80 \\
\hline \multicolumn{3}{|l|}{ Smoking } \\
\hline Yes & 229 & 65.06 \\
\hline No & 123 & 34.94 \\
\hline \multicolumn{3}{|l|}{ Drinking } \\
\hline Yes & 79 & 22.40 \\
\hline No & 273 & 77.60 \\
\hline \multicolumn{3}{|l|}{ Heart disease } \\
\hline Yes & 113 & 32.10 \\
\hline No & 239 & 67.90 \\
\hline \multicolumn{3}{|l|}{ Family heart disease } \\
\hline Yes & 76 & 21.60 \\
\hline No & 276 & 78.40 \\
\hline
\end{tabular}

related to the severity of air pollution in the study area. During the study period (01 January 2017-31 December 2018), poor air quality was indicated on only $7 \%$ of the days in the Taoyuan area, whereas in the Taichung area, this percentage was $30 \%$. This result conforms to the findings in our analysis using a health insurance database, and the occurrence of acute myocardial infarction was positively correlated with average air pollution severity in the study area (unpublished data).
Table 2 Demographic and medical-related variables of the patients from Taichung Hospital

\begin{tabular}{|c|c|c|}
\hline \multirow[t]{2}{*}{ Acute myocardial infraction } & \multirow[b]{2}{*}{ Number } & \multirow[b]{2}{*}{ Percentage } \\
\hline & & \\
\hline Total & 278 & 100.00 \\
\hline \multicolumn{3}{|l|}{ Sex } \\
\hline Male & 199 & 71.58 \\
\hline Female & 79 & 28.42 \\
\hline Age & $66.16 \pm 16.71$ & \\
\hline \multicolumn{3}{|l|}{ Age group (years) } \\
\hline$<45$ & 46 & 16.55 \\
\hline $45-65$ & 99 & 35.61 \\
\hline$>65$ & 133 & 47.84 \\
\hline BMI $\left(\mathrm{kg} / \mathrm{m}^{2}\right)$ & $26.18 \pm 4.31$ & \\
\hline$<18.5$ & 3 & 1.08 \\
\hline 18.5 to $<25$ & 109 & 39.21 \\
\hline 25 to $<30$ & 122 & 43.88 \\
\hline$\geq 30$ & 44 & 15.83 \\
\hline \multicolumn{3}{|l|}{ Hypertension } \\
\hline Yes & 199 & 71.58 \\
\hline No & 79 & 28.42 \\
\hline \multicolumn{3}{|l|}{ Hyperlipidemia } \\
\hline Yes & 93 & 33.45 \\
\hline No & 185 & 66.55 \\
\hline \multicolumn{3}{|l|}{ Diabetes mellitus } \\
\hline Yes & 127 & 45.68 \\
\hline No & 151 & 54.32 \\
\hline \multicolumn{3}{|l|}{ Smoking } \\
\hline Yes & 187 & 67.27 \\
\hline No & 91 & 32.73 \\
\hline \multicolumn{3}{|l|}{ Drinking } \\
\hline Yes & 96 & 34.53 \\
\hline No & 182 & 65.47 \\
\hline \multicolumn{3}{|l|}{ Heart disease } \\
\hline Yes & 83 & 29.86 \\
\hline No & 195 & 70.14 \\
\hline \multicolumn{3}{|l|}{ Family heart disease } \\
\hline Yes & 67 & 24.10 \\
\hline No & 211 & 75.90 \\
\hline
\end{tabular}

Similar findings have been reported in systematic reviews. In area with low severity of air pollution, short-term pollutant exposure did not increase the incidence of acute myocardial infarction (Milojevic et al. 2014; Wichmann et al. 2014; Wolf et al. 2015). Studies conducted in areas with moderate or high severity of air pollution have reported a positive correlation between short-term exposure to pollution and the incidence of acute myocardial infarction (Xu et al. 2017a, b; Ye et al. 2016; Liu et al. 2015; Yu et al. 2018). 
Table 3 Demographic and medical-related variables of the cases collected from Taoyuan Hospital and Taichung Hospital

\begin{tabular}{llll}
\hline & Taoyuan Hospital $(N=352)$ & Taichung Hospital $(N=278)$ & $P$ \\
\hline Age, y & $62.90 \pm 14.89$ & $66.16 \pm 16.71$ & 0.51 \\
Male sex, $n(\%)$ & $269(76.40)$ & $199(71.58)$ & 0.44 \\
BMI $\left(\mathrm{kg} / \mathrm{m}^{2}\right)$ & $27.51 \pm 4.07$ & $26.18 \pm 4.31$ & 0.85 \\
Hypertension, $n(\%)$ & $244(69.30)$ & $199(71.58)$ & 0.53 \\
Hyperlipidemia, $n(\%)$ & $65(18.50)$ & $93(33.45)$ & 0.16 \\
Diabetes mellitus, $n(\%)$ & $131(37.20)$ & $127(45.68)$ & 0.43 \\
Smoking, $n(\%)$ & $229(65.06)$ & $187(67.27)$ & 0.62 \\
Drinking, $n(\%)$ & $79(22.40)$ & $96(34.53)$ & 0.27 \\
Heart disease, $n(\%)$ & $113(32.10)$ & $83(29.86)$ & 0.34 \\
Family heart disease, $n(\%)$ & $76(21.60)$ & $67(24.10)$ & 0.55 \\
\hline
\end{tabular}

Wolhuter et al. (2021) used two major events in 2020, namely, the Australian bushfires and the COVID-19 pandemic lockdown, to illustrate the relationship between air pollution and cardiovascular disease. The Australian bushfires led to severe air pollution and increased the incidence of cardiovascular disease. Conversely, the COVID-19-related lockdown demonstrated that air pollutants can be effectively reduced, which lead to the potential reduction of cardiovascular disease events. Further, Giani et al. (2020) demonstrated that China and Europe experienced the short-term and long-term health effects of reduced air pollution due to the COVID-19 lockdown.

A patient's chronic health conditions can affect their susceptibility to acute myocardial infarction, but these factors are usually not measured accurately (Pope et al. 2015; Wolf et al. 2015). In 1991, Maclure et al. proposed the case-crossover study design, which is a method for studying transient effects on the risk of acute events. Our study employed a 2-week time interval; the air pollution level during the acute myocardial infarction event was compared with that 2 weeks before the event. This study design can reduce individual differences and the influence of confounding factors (Maclure 1991).

The mechanism through which long-term exposure to air pollution leads to cardiovascular disease development has

Table 4 Incidence of short-term exposure to ambient air pollutants and acute myocardial infarction in the patients from Taoyuan Hospital

Poisson regression in the generalized linear model

\begin{tabular}{lllll}
\hline & OR & $95 \% \mathrm{CI}$ & $95 \% \mathrm{CI}$ & $P$ \\
\hline $\mathrm{PM}_{2.5}$ & 1.006 & 0.995 & 1.017 & 0.315 \\
$\mathrm{PM}_{10}$ & 0.996 & 0.988 & 1.003 & 0.253 \\
$\mathrm{NO}_{2}$ & 0.998 & 0.975 & 1.021 & 0.848 \\
$\mathrm{SO}_{2}$ & 1.051 & 0.897 & 1.233 & 0.536 \\
$\mathrm{O}_{3}$ & 1.005 & 0.995 & 1.014 & 0.345 \\
\hline
\end{tabular}

$O R$ odds ratio: adjusted variables listed in the table, $C I$ confidence interval been proven; this can increase oxidative stress (OS), inflammatory stress, and vascular endothelial damage, leading to atherosclerosis (Seaton et al. 1995; Brook et al. 2004; Kodavanti et al. 2002). OS and inflammatory stress also influence many neurological diseases; however, no effective and safe treatment is available for neurological diseases. Rahman et al. (2021) reported that molecular hydrogen $\left(\mathrm{H}_{2}\right)$ is an antioxidant and an anti-inflammatory agent. It can be used for the prevention, treatment, and mitigation of $\mathrm{H}_{2}$ administration. However, the efficacy of $\mathrm{H}_{2}$ in preventing coronary atherosclerosis remains unknown.

COVID-19 infection mainly affects the respiratory system. However, an increasing number of studies reported neurological and cardiovascular abnormalities, as well. Furthermore, cardiovascular and neurological diseases are likely to be underlying causes of the risk of severe COVID-19 infection. To reduce the impact of neurological and cardiovascular diseases on patients with COVID-19, detailed risk analysis and the development of comprehensive management strategies are necessary (Sharma et al. 2021). In cardiovascular diseases, atherosclerosis leads to coronary artery stenosis, which takes time to accumulate. Long-term exposure to air pollution increases latent cardiovascular diseases. Short-term exposure to air pollution can produce OS and inflammation, increase the

Table 5 Incidence of short-term exposure to ambient air pollutants and acute myocardial infarction in the patients from Taichung Hospital

Poisson regression in the generalized linear model

\begin{tabular}{lllll}
\hline & OR & $95 \% \mathrm{CI}$ & $95 \% \mathrm{CI}$ & $P$ \\
\hline $\mathrm{PM}_{2.5}$ & 1.021 & 1.002 & 1.040 & 0.026 \\
$\mathrm{PM}_{10}$ & 1.010 & 1.001 & 1.020 & 0.035 \\
$\mathrm{NO}_{2}$ & 0.997 & 0.988 & 1.007 & 0.551 \\
$\mathrm{SO}_{2}$ & 1.002 & 0.985 & 1.021 & 0.788 \\
$\mathrm{O}_{3}$ & 1.007 & 1.000 & 1.014 & 0.057 \\
\hline
\end{tabular}

$O R$ odds ratio: adjusted variables listed in the table, $C I$ confidence interval 
burden on the heart, and trigger latent cardiovascular diseases. This explains why short-term exposure to air pollutants in areas with severe air pollution increases the risk of acute myocardial infarction.

This study has three strengths. First, we used medical records from two hospitals, and all patients were identified as having acute myocardial infarction based on records of cardiac catheterization. Second, we could confirm that all patients had been active near the hospital for a long time; therefore, the air pollution data from the corresponding monitoring station could represent the patient's exposure to air pollutants. Third, we compared the condition of the day of onset of disease with that on the same day 2 weeks prior to eliminate the effect of changes in patient's lifestyle and physical illness.

This study has two limitations. First, we could not determine the true air pollution exposure of the patients, which would have been affected by the use of protective equipment or working indoors. Second, we employed medical records from only two hospitals for analysis and research. The study results revealed a positive correlation in an area with high severity of air pollution but no correlation in an area with low severity of air pollution. We were unable to define high severity of air pollution precisely; doing so would require more research data.

\section{Conclusion}

The difference in the severity of regional air pollution has a serious short-term impact on the risk of acute myocardial infarction. Therefore, to fully prevent acute myocardial infarctions caused by exposure to ambient air pollutants, relevant laws and regulations should be complied with to control the level of ambient air pollutants to the greatest extent possible and thus reduce people's exposure to air pollutants.

\footnotetext{
Acknowledgements We thank Taiwan's Air Quality Monitoring Station of the Environmental Protection Agency of the Executive Yuan for providing us the air pollution data; Taoyuan and Taichung hospitals for providing medical information. Thanks to Enago (www.enago. tw) for providing professional language editing, and proofreading (EnagoCertificate-YENCUT-1).
}

Author contribution C.-C.Y. was responsible for study design, acquisition, analysis and interpretation of data, and drafting the manuscript. P.L.C. contributed to the design and interpretation of the analysis and drafting and critical revision of the manuscript. All authors provided approval for the final version of the manuscript and agree to be accountable for all aspects of the work.

Data availability The air pollution data was provided by the Protection Agency of the Executive Yuan (https://airtw.epa.gov.tw/). The full datasets used in this analysis are available from the corresponding author on reasonable request.

\section{Declarations}

Ethics approval The present study was approved by the Institutional Review Board of Tri-Service General Hospital, and all procedures were in accordance with prevailing ethical principles.

Consent to participate This is a retrospective case study. All cases have been treated before data collection to avoid patient identification. Therefore, patients' informed consent was not required.

Consent for publication Not applicable.

Conflict of interest The authors declare no competing interests.

\section{References}

Brook RD, Brook JR, Urch B, Vincent R, Rajagopalan S, Silverman F (2002) Inhalation of fine particulate air pollution and ozone causes acute arterial vasoconstriction in healthy adults. Circulation 105(13): $1534-1536$

Brook RD, Franklin B, Cascio W, Yuling H, George H, Michael L (2004) Air pollution and cardiovascular disease: a statement for healthcare professionals from the Expert Panel on Population and Prevention Science of the American Heart Association. Circulation 109(21): 2655-2671

Giani P, Castruccio S, Anav A, Howard D, Hu W, Crippa P (2020) Shortterm and long-term health impacts of air pollution reductions from COVID-19 lockdowns in China and Europe: a modelling study. Lancet Planet Health 4:e474-e482

Kodavanti UP, Schladweiler Mette CJ, Ledbetter AD, Russ H, Christiani DC, Samet JM (2002) Pulmonary and systemic effects of zinccontaining emission particles in three rat strains: multiple exposure scenarios. Toxicol Sci 70(1):73-85

Lelieveld J, Klingmüller K, Pozzer A, Poschl U, Fnais M, Daiber A, Munze T (2019) Cardiovascular disease burden from ambient air pollution in Europe reassessed using novel hazard ratio functions. Eur Heart J 40:1590-1596

Lelieveld J, Pozzer A, Pöschl U, Fnais M, Haines A, Münzel T (2020) Loss of life expectancy from air pollution compared to other risk factors: a worldwide perspective. Cardiovasc Res 116:1910-1917

Liu Y, Chen X, Huang S, Tian L, Lu Y'a, Mei Y (2015) Association between air pollutants and cardiovascular disease mortality in Wuhan, China. Int J Environ Res Public Health 12(4):3506-3516

Maclure M (1991) The case-crossover design: a method for studying transient effects on the risk of acute events. Am J Epidemiol 133(2):144-153

Miller KA, Siscovick DS, Sheppard L, Shepherd K, Sullivan JH, Anderson GL (2007) Long-term exposure to air pollution and incidence of cardiovascular events in women. N Engl J Med 356(5): $447-458$

Milojevic A, Wilkinson P, Armstrong B, Bhaskaran K, Smeeth L, Hajat S (2014) Short-term effects of air pollution on a range of cardiovascular events in England and Wales: case-crossover analysis of the MINAP database, hospital admissions and mortality. Heart 100(14):1093-1098

Oikonomou E, Mystakidi VC, Theofilis P, Fountoulakis P, Asimakopoulou M, Barbaresos N, Giannarakis I, Vogiatzi G, Papakonstantinou M, Tsalamandris S, Lazaros G, Tousoulis D (2020) The impact of air pollution on atherosclerosis burden in patients with coronary artery disease. J Am Coll Cardiol 75:34633463 
Pekkanen J, Peters A, Hoek G, Tiittanen P, Brunekreef B, de Hartog J (2002) Particulate air pollution and risk of ST-segment depression during repeated submaximal exercise tests among subjects with coronary heart disease: the Exposure and Risk Assessment for Fine and Ultrafine Particles in Ambient Air (ULTRA) study. Circulation 106(8):933-938

Pope CA 3rd, Muhlestein JB, May HT, Renlund DG, Anderson JL, Horne BD (2006) Ischemic heart disease events triggered by shortterm exposure to fine particulate air pollution. Circulation 114(23): 2443-2448

Pope BA, Muhlestein JB, Anderson JL (2015) Short-term exposure to fine particulate matter air pollution is preferentially associated with the risk of ST-segment elevation acute coronary events. J Am Heart Assoc 4:e02506

Rahman MH, Bajgai J, Fadriquela A, Sharma S, Trinh Thi T, Akter R, Goh SH, Kim CS, Lee KJ (2021) Redox effects of molecular hydrogen and its therapeutic efficacy in the treatment of neurodegenerative diseases. Processes 9:308. https://doi.org/10.3390/ pr9020308

Rao X, Zhong J, Brook RD, Rajagopalan S (2018) Effect of particulate matter air pollution on cardiovascular oxidative stress pathways. Antioxid Redox Signal 28(9):797-818

Seaton A, Godden D, MacNee W, Donaldson K (1995) Particulate air pollution and acute health effects. Lancet 345(8943):176-178

Sharma S, Batra S, Gupta S, Sharma VK, Rahman MH, Kamal MA (2021) Persons with co-existing neurological disorders: risk analysis, considerations and management in COVID-19 pandemic. CNS Neurol Disord Drug Targets 20. https://doi.org/10.2174/ 1871527320666210308113457

Sun Q, Hong X, Wold LE (2010) Cardiovascular effects of ambient particulate air pollution exposure. Circulation 121(25):2755-2765

Wichmann J, Sjöberg K, Tang L, Haeger EM, Rosengren A, Andersson Eva M (2014) The effect of secondary inorganic aerosols, soot and the geographical origin of air mass on acute myocardial infarction hospitalizations in Gothenburg, Sweden during 1985-2010: a casecrossover study. Environ Health 13:61

Wolf K, Schneider A, Breitner S, Meisinger C, Heier M, Cyrys J (2015) Associations between short-term exposure to particulate matter and ultrafine particles and myocardial infarction in Augsburg, Germany. Int J Hyg Environ Health 218(6):535-542

Wolhuter K, Arora M, Kovacic JC (2021) Air pollution and cardiovascular disease: can the Australian bushfires and global COVID-19 pandemic of 2020 convince us to change our ways? Bioessays 9: e2100046. https://doi.org/10.1002/bies.202100046

World Health Organization (WHO) (2016) Available from: http://www. who.int/mediacentre/factsheets/fs310/en/. Accessed 20 Mar 2021

Xie W, Li G, Zhao D, Xie X, Wei Z, Wang W (2015) Relationship between fine particulate air pollution and ischemic heart disease morbidity and mortality. Heart 101(4):257-263

Xu A, Zhe M, Bo J, Wang W, Yu H, Lijuan Z (2017a) Acute effects of particulate air pollution on ischemic heart disease hospitalizations in Shanghai, China. Int J Environ Res Public Health 14(2):168

Xu Q, Shuo W, Yuming G, Chao W, Fangfang H, Xia L (2017b) Acute exposure to fine particulate matter and cardiovascular hospital emergency room visits in Beijing, China. Environ Pollut 220(Pt A):317327

Ye X, Peng L, Kan H, Wang W, Geng F, Mu Z (2016) Acute effects of particulate air pollution on the incidence of coronary heart disease in Shanghai, China. PLoS One 11(3):e0151119

Yu Y, Shen Y, Dong H, Minghui J, Zhiyong C, Guiying L (2018) Shortterm effects of ambient air pollutants and myocardial infarction in Changzhou, China. Environ Sci Pollut Res Int 25(22):22285-22293

Publisher's note Springer Nature remains neutral with regard to jurisdictional claims in published maps and institutional affiliations. 